\title{
A evolução da concentração sectorial em Portugal entre 1995 e 2006: a perspetiva do índice de Herfindahl-Hirschman
}

\author{
The evolution of the sectoral concentration in Portugal between 1995 and 2006: the Herfindahl- \\ Hirschman index perspective
}

\section{Elsa de Morais Sarmento}

Departamento de Economia, Gestão e Engenharia, Universidade de Aveiro, Campus Universitário de Santiago, 3810-193, Aveiro, Portugal, esarmento@ua.pt

\section{Alcina Nunes}

Escola Superior de Tecnologia e Gestão, Instituto Politécnico de Bragança, 5300-253, Bragança, Portugal, Grupo de Estudos Monetários e Financeiros (GEMF) da Faculdade de Economia da Universidade de Coimbra, alcina@ipb.pt

\section{Resumo}

Este estudo fornece uma análise comparativa sobre a evolução do grau de concentração de diferentes sectores económicos, através do cálculo de índices Herfindahl-Hirschman, obtidos a partir de duas das principais fontes de informação sobre as empresas em Portugal, os Quadros de Pessoal do Ministério do Trabalho e da Solidariedade Social (1995-2006) e o Sistema de Contas Integrado das Empresas do Instituto Nacional de Estatística (2004-2006), aos quais foi aplicada a metodologia do "Manual da Demografia de Empresas" do Eurostat e da OCDE. A análise por secção da Classificação das Atividades Económicas (CAE Rev. 2.1.) é posteriormente desagregada a dois dígitos. Entre 2004 e 2006, os sectores de mais elevada concentração são a "Fabricação de coque, produtos petrolíferos refinados e tratamento de combustível nuclear", a "Produção, distribuição de eletricidade" e os "Transportes Aéreos", em linha com a literatura internacional.

Keywords: Concentração, sectores, índice Herfindahl-Hirschman, Portugal.

\section{Abstract}

This study provides a comparative analysis of the evolution of the degree of concentration of different economic sectors, through the Herfindahl-Hirschman-Index, obtained from the two main sources of enterprise information in Portugal, the Quadros de Pessoal database from the Ministry of Labour and Social Solidarity (19952006) and the Integrated System of Accounts from Statistics Portugal (2004-2006), to which the methodology of the "Manual of Business Demography Statistics" from the Eurostat and the OECD was applied to. The classification of economic activities (CAE Rev. 2.1) is further broken down to two digits in the analysis provided. Between 2004 and 2006, the sectors of highest concentration are "Manufacture of coke, refined petroleum products and nuclear fuel", "Production and distribution of electricity" and "Air Transport", in line with the results of the international related literature.

Keywords: Concentration, sectors, Herfindahl-Hirschman Index, Portugal.

\section{Introdução}

O fenómeno da concentração industrial tornou-se uma preocupação central de economistas e decisores políticos nas últimas décadas. Este interesse emergiu em parte devido a processos de integração regional que ocorreram na segunda metade do século $\mathrm{XX}$, que muito inspiraram correntes como a nova geografia económica, mas também devido a outros fenómenos, como a emergência de multinacionais, das cadeias globais de valor, da aceleração dos investimento direto estrangeiro a nível mundial e da própria globalização. Acresce que em termos microeconómicos, o sucesso da atividade empresarial é cada vez mais determinado pelas condições de mercado onde a empresa opera, nomeadamente pelas condições de concorrência existentes. No entanto, a aferição da concentração não tem tido a merecida atenção. Esta baseiase ainda na utilização de medidas clássicas, algumas delas já ultrapassadas e desfasadas da realidade dos mercados atuais, da disponibilidade de informação estatística necessária ao seu cálculo e do esforço computacional exigido (Ginevičius \& Čirba, 2009).

Em Portugal, escasseia a informação atualizada sobre a concentração industrial. Com exceção do documento de Faustino (1995), do trabalho de Barrios, Bertinelli, Strobl e Teixeira (2005), que compara as dinâmicas de aglomeração entre a economia portuguesa e a irlandesa, e da investigação desenvolvida por Amador e Soares (2012) relativa à concorrência nos sectores transacionável e não transacionável da economia portuguesa, o tema da concentração per se tem sido pouco estudado. Têm sido igualmente pouco explorados na literatura os efeitos da reestruturação industrial sobre o grau de concentração económica. No entanto, alguma evidência mais recente aplicada às regiões portuguesas aponta para que, para além das habituais características territoriais a nível de mão-deobra e diversificação económica, também especificidades de concorrência a nível regional podem afetar o crescimento empresarial. Os resultados de Barbosa e Eiriz (2011: 152) indicam que as empresas portuguesas têm vindo a beneficiar mais em termos de crescimento por via da existência de uma variedade de indústrias na sua região, do que da diversidade industrial, "confirmado as implicações do conceito Marshaliano de economias de aglomeração".

Efetivamente, a produção do Índice de HerfindahlHirschman (IHH) pelas entidades oficiais de estatística tem sido menosprezada devido à aparente desconexão entre o IHH e medidas mais padronizadas de concentração, como o coeficiente de Gini. No entanto, isto não se deve atribuir à falta de disponibilidade de informação estatística para o cálculo deste indicador. Daqui decorre que as implicações do IHH em termos da sua influência na tomadas de decisão económica tem também sido bastante limitada, à exceção da utilização feita pelas Autoridades de Concorrência pelo 
mundo fora, embora esteja em geral restrita a situações específicas em que se analisam determinados mercados relevantes ou quando se pretende que se respeitem regras de concentração horizontal.

É prática comum na literatura da organização industrial uma abordagem à estrutura de mercado através de medidas de concentração. A importância da utilização de indicadores de concentração deriva da sua capacidade de captar características estruturais de um mercado ou sector económico. Os rácios de concentração são frequentemente usados na modelização económica para explicar a performance competitiva no sector bancário ou energético, por exemplo mas não exclusivamente, em resultado da estrutura de mercado existente (Bikker \& Haaf, 2002). No entanto, esta aproximação não tem sido pacífica, dada a reconhecida multidimensionalidade das estruturas de mercado, o que torna a sua medição uma questão controversa. Tem sido mais utilizada a definição de um conjunto de características que, em conjunto possam ser utilizadas para descrever uma determinada estrutura de mercado (ver por exemplo, Bain, 1968).

Nas últimas décadas foram várias as medidas especificamente desenvolvidas para aferir o grau de concentração da atividade económica em diferentes sectores, indústrias (Blackorby, Donaldson \& Weymark., 1982; Resende \& Wyllie, 2005; Ginevičius \& Čirba, 2009), regiões (Ellison \& Glaeser, 1997), e também, relativamente à posição dominante de empresas individuais (Melnik, Shy \& Stenbacka, 2008). No entanto, a grande maioria dos estudos efetuados têm vindo a focar-se sobretudo, na medição da concentração das atividades do sector industrial e nos seus determinantes.

A análise de concentração sectorial para a economia portuguesa apresentada neste paper, baseia-se no cálculo de índices de concentração Herfindahl-Hirschman ao longo do período compreendido entre 1995 e 2006, para um conjunto alargado de sectores económicos, categorizados estatisticamente segundo a Classificação das Atividades Económicas (CAE Rev. 2.1) a dois dígitos e a uma letra. Para além do sector industrial, habitual em análises desta natureza, abordam-se igualmente a agricultura, silvicultura, caça e pesca, os sectores da eletricidade, gás e água, bem como a construção e um conjunto de sectores ligados ao comércio e aos serviços, privados e públicos. É aplicada a metodologia do "Manual of Business Demography Statistics" (Eurostat \& OCDE, 2007), a duas bases de dados distintas: aos Quadros de Pessoal, do Ministério do Trabalho e da Segurança Social, e ao Sistema de Contas Integrado das Empresas (SCIE), do Instituto Nacional de Estatística (INE). São posteriormente analisadas, de forma meramente descritiva, e comparadas tendências e padrões de concentração ao longo deste período segundo cada uma destas duas fontes de informação.

Este artigo encontra-se organizado em 5 secções. Na secção seguinte descrevem-se, numa perspetiva de análise da literatura, os aspetos metodológicos relevantes para a análise efetuada, e na secção 3, os dados, com base nas duas fontes de informação consideradas, os Quadros de Pessoal e o Sistema de Contas Integrado. A secção 4 é dedicada à apresentação e comparação dos índices de concentração por sector. Por último, a secção 5 expõe algumas considerações finais.

\section{0 Índice de Herfindahl-Hirschman numa perspetiva crítica}

Os dados sobre a distribuição da dimensão empresarial (onde se utilizam preferencialmente empresas a estabelecimentos) podem ser usados para fornecer uma indicação do nível de concentração ou, por outro lado, de concorrência nos diferentes sectores económicos. Estas medidas de concentração são tipicamente, utilizadas para avaliar a estrutura de mercado de uma indústria ou sector e aferir a distância dessa indústria face a uma situação de concorrência perfeita ou de monopólio.

Inicialmente, os estudos sobre este tema limitavam-se à contagem de empresas, no qual o grau de concentração das vendas era descrito pelo número e distribuição de tamanho dos vendedores nesse mercado (Adelman, 1951). Mais tarde, priviligiou-se o grau de concentração das vendas, medida pelo número e distribuição das maiores empresas num mercado. Mais tarde, utilizaram-se medidas de intensidade para aferir a concentração, intituladas de índices, segundo um esquema de ponderações que medem a participação que cada empresa detém num determinado mercado.

Nas últimas décadas, a forma mais habitual de avaliar o poder de mercado em diversas indústrias ou mercados tem sido via a utilização de índices de concentração (Rhoades, 1993). Uma primeira caraterização dos índices de concentração refere-se à sua classificação entre medidas parciais ou sumárias. Os índices sumários consideram toda a informação da população amostral e não apenas as maiores empresas. Dentro desta categoria incluem-se os índices de Herfindahl (Herfindahl, 1950) e de Theil. Outra tipologia de caraterização distingue entre índices discretos e cumulativos (Ginevičius \& Čirba, 2007). As medidas cumulativas de concentração consideram toda a distribuição das empresas por dimensão, o que implica que alterações estruturais em todas as partes da distribuição influenciam o valor do índice de concentração. Esta característica é apresentada pelo índice de HerfindahlHirschman (IHH), que se tornou na medida de concentração mais popular a nível internacional, habitualmente utilizado pelas Autoridades de Concorrência a nível mundial e adotado pela Organização de Cooperação e Desenvolvimento Económico (OCDE) para caraterizar a concentração dos mercados do ponto de vista da demografia empresarial (OECD, 2008; OECD, 2006). De facto, este índice tem sido amplamente utilizado no controlo de concentrações horizontais de empresas estando incluído nas linhas gerais de atuação do Departamento de Justiça dos EUA (Shapiro, 2010) e da Comissão Europeia (UE) para avaliar ex-ante este tipo de concentrações (McIntosh \& Hellmer, 2012; Melnik et al., 2008).

A principal hipótese na qual se baseia o IHH é a de que o poder de mercado está diretamente relacionado com o grau de concentração nesse mercado. O IHH é o índice tradicionalmente mais utilizado na literatura teórica como medida de concentração, servindo frequentemente de 
benchmark para situações onde esta avaliação é feita com recurso a outros índices de concentração. É, também, muitas vezes denominado de índice de informação completa (full-information index) porque captura as características de toda a distribuição das empresas por dimensão. 0 cálculo deste indicador requer informação individualizada de cada empresa, logo requer bases de suporte com micro dados empresariais, por vezes difíceis de aceder (Kelly, 1981).

Já Scherer (1965) e Scherer et al. (1987), ou mais recentemente Matsumoto, Merlone e Szidarovszky (2012), advertiam sobre os cuidados a ter na interpretação do significado da concentração de mercado. A literatura aplicada há muito que critica a utilização de rácios de concentração como sendo frágeis medidas de avaliação do poder de mercado, sujeitas, por vezes, a erros grosseiros. $\mathrm{O} \mathrm{IHH}$, nomeadamente, tem sido acusado de ser um indicador excessivamente estático, demasiadamente sensível à definição de mercado, comparativamente mais insensível a pequenas empresas e start-ups (Ginevičius \& Čirba, 2007) e, de algum modo, enviesado. Isto porque não reflete na quota de mercado das empresas, a concorrência latente ou a pressão das importações. Cabe ainda ressaltar que, como o IHH é um indicador calculado para um determinado mercado apenas, não pode ser aplicado a empresas que operem em múltiplos mercados. Mas, talvez, o aspeto de mais difícil resolução é que, na presença de regimes de propriedade cruzada (cross-ownership), o IHH revela deficiências na exatidão do cálculo do verdadeiro nível de concorrência do mercado (Demsetz \& Lehn, 1985; Campos \& Vega, 2004).

No entanto, em geral estas críticas são relativamente fáceis de resolver através de ajustamentos menores ao índice (Campos \& Vega, 2004). Incontestável é o facto do IHH cumprir as seis propriedades desejáveis de Hall e Tideman (1967), sendo também considerado superior a muitos outros indicadores em testes de comparação de precisão (Ginevičius \& Čirba, 2009). Com efeito, o IHH tem sido frequentemente utilizado na literatura de organização industrial, não só por se encontrar devidamente suportado pela teoria económica, mas também por apresentar propriedades superiores relativamente a medidas mais simplificadas (Weinstock, 1982), designadamente a rácios de concentração empresarial. Não só contempla todas as empresas, como consegue captar toda a distribuição dimensional das empresas de um determinado mercado.

O IHH é no fundo uma medida da dimensão das empresas relativamente à indústria/sector onde se encontram e é um indicador de concentração ou concorrência entre estas. De acordo com a OCDE (2006), para uma indústria com $n$ empresas, o índice de Herfindahl-Hirschmann é definido como:

$$
I H H=\sum_{i=1}^{n}\left\lfloor\frac{X_{i} \times 100}{\sum_{1}^{n} X_{i}}\right\rfloor
$$

Onde $X_{i}$ é uma medida apropriada para a dimensão da empresa. Neste caso, foi utilizado o volume de vendas para cada empresa $i$.

O IHH é, também, frequentemente representado por $I H H=$ $\sum_{i=1}^{n} s_{i}^{2}, \quad$ onde $s_{i}=\frac{X_{i}}{\sum_{i=1}^{n} X_{i}}, \operatorname{com} i=1, \ldots, n$. Nesta formulação, o IHH é definido como a soma dos quadrados das quotas de mercado de cada empresa individual $\left(\sum_{t=1}^{n} s_{i}^{2}\right)$ presente nesse mercado ou sector (OECD, 2008), onde $s_{i}$ é a quota de mercado da empresa $i$ no mercado (ou seja, a percentagem de participação no total da iésima empresa) e $n$ é o número de empresas. Uma diminuição do índice IHH indica geralmente uma perda de poder de influência sobre os preços (pricing power) e uma diminuição da concentração e vice-versa (Kelly, 1981).

Os seus limites superiores e inferiores traduzem-se na seguinte expressão: $1 / n \leq I H H \leq 1$. À medida que o número de empresas aumenta, o limite inferior diminui. Uma limitação do IHH é que à medida que o número de empresas varia, o limite inferior $(1 / \mathrm{n})$ também se altera limitando a sua comparabilidade internacional. No entanto, é possível realizar ajustamentos para garantir a comparabilidade (ver, por exemplo, Resende (1994)). Quando este número tende para o infinito, o valor do índice tende para zero. A convenção adotada internacionalmente pelas entidades reguladoras é a de multiplicar a quota de mercado por 100 , de forma que o IHH varie entre zero (concorrência perfeita) e 10.000 (monopólio). O IHH é zero, no caso de existirem muitos atores no mercado, cada um deles com participação mínima, dividindo o mercado de igual forma, até 10.000 , onde existe um único agente no mercado, com $100 \%$ de participação. A utilização do IHH na análise de concentrações convencionou que um mercado é considerado "não concentrado", caso o seu IHH seja menor que 1.000, moderadamente concentrado" caso o IHH esteja entre 1.000 e 1.800 e é considerado "altamente concentrado" se o IHH for superior a 1.800 .

\section{Dados estatísticos}

A primeira parte deste trabalho assenta numa base de dados específica, obtida a partir da aplicação da metodologia baseada no "Manual of Business Demography Statistics" (Eurostat \& OECD, 2007), aos Quadros de Pessoal do Gabinete de Estratégia e Planeamento do Ministério do Trabalho e da Segurança Social. Consideraram-se, para efeitos do cálculo dos índices IHH, apenas empresas ativas empregadoras, ou seja, empresas que empreguem pelo menos um trabalhador. De acordo com o Manual (Eurostat \& OECD, 2007), a concentração de empresas reporta-se a eventos demográficos (concentrações e take-overs) que envolvam mais do que uma empresa num momento inicial e apenas uma empresa num momento final, depois do evento. 0 termo também pode ser aplicado para descrever a diminuição de proprietários de uma população de empresas ou também uma situação onde a população de empresas se torne mais dispersa por um número mais reduzido de grupos de empresas (European Communities, 2003, parágrafos 13.18 a 13.19). A base de dados que decorre da aplicação da metodologia Eurostat/OCDE contém numa média anual de 215.903 empresas empregadoras ativas no período de 1985 a 2007, com 36.803 nascimentos e 23.743 mortes de empresas (para mais informações consultar Sarmento \& Nunes, 2014 e Sarmento \& Nunes, 2010). Em 2007, esta apresentava 354.920 empresas ativas, 44.611 nascimentos e em 2005 um total de 38.082 mortes. Apresentam-se as mortes de empresas apenas até 2005 
porque de acordo com a metodologia considerada, deve-se verificar dois anos após o último registo da empresa que esta não foi entretanto reativada. Dado que os dados disponíveis neste estudo são até ao ano de 2007, apenas foi possível confirmar até 2005 as mortes das empresas, de acordo com a metodologia proposta.

A segunda parte deste trabalho assenta nos índices de concentração calculados pelo Instituto Nacional de Estatística (INE), baseados na aplicação da metodologia supracitada (Eurostat \& OECD, 2007) à base de dados do Sistema de Contas Integrado das Empresas (SCIE) (para mais informações consultar a nota metodológica sobre o SCIE do Instituto Nacional de Estatística (INE, 2010)). Esta população de "empresas" é mais alargada do que a dos Quadros de Pessoal, contendo em 2007, 1.033.984 empresas empregadoras (Figura 1).

\section{Figura 1 - Comparação entre a população de empresas empregadoras

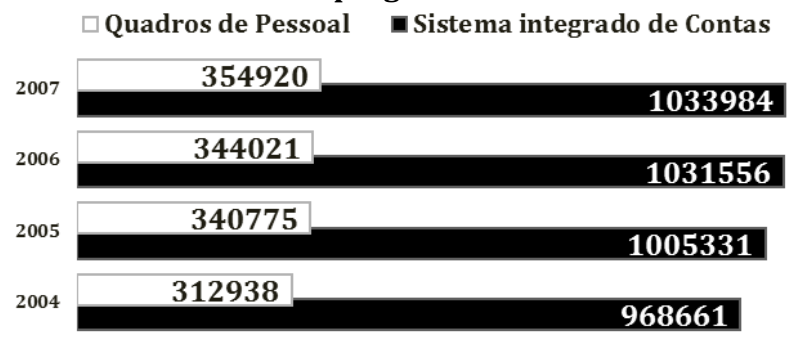

Fonte: Dados do INE provenientes do Sistema de Contas Integrado das Empresas (SCIE) e cálculos próprios para os Quadros de Pessoal (GEP/MTSS).

Estas diferenças devem-se, entre outros fatores, ao facto de que que nos Quadros de Pessoal apenas aparecem empresas com trabalhadores registados na Segurança Social (para mais informações consultar Instituto Nacional de Estatística
(2010) e Sarmento e Nunes (2014)). A partir de 2004, os dados das Estatísticas das Empresas do INE apresentam uma quebra de série, devido a questões metodológicas que se prendem essencialmente com a inclusão dos profissionais liberais e com a utilização de informação exaustiva em detrimento dos dados extrapolados do Inquérito Anual às Empresas (por amostragem). Assim sendo, os dados produzidos a partir de 2004, inclusive, não são diretamente comparáveis com os divulgados em anos anteriores, por isso os índices IHH do INE são apresentados, nas secções seguintes, apenas para o período entre 2004 e 2006.

As características destas duas bases de dados tornam-nas particularmente apropriadas ao estudo do fenómeno da concentração. Em primeiro lugar, são bases de dados exaustivas, que cobrem praticamente todas as empresas do país que operam no mercado formal. Em segundo lugar, a sua dimensão longitudinal permite captar a dinâmica empresarial e acompanhar as empresas ao longo do seu ciclo de vida. Dadas as quebras de série nas Estatísticas das Empresas a partir de 2004, a sua comparabilidade está restrita à dimensão longitudinal comum existente entre 2004 e 2006.

\section{Resultados}

\subsection{Quadros de Pessoal}

A Tabela 1 apresenta índices de Herfindahl-Hirschman para o período compreendido entre 1995 e 2006 a uma letra da CAE Rev. 2.1., obtidos a partir dos Quadros de Pessoal. Apenas é considerado o período posterior a 1995 e anterior a 2007 devido a quebras de série relacionadas, nomeadamente, com a introdução de novas versões da CAE. A comparação com momentos de tempo anteriores a 1995 e posteriores a 2006 não é estritamente comparável e assim a opção pela sua não análise, neste trabalho.

\section{Tabela 1 - Índices de concentração HHI a 1 letra da CAE Rev. 2.1, entre 1995 e 2006, calculados com base na} informação dos Quadros de Pessoal

\begin{tabular}{|c|c|c|c|c|c|c|c|c|c|c|c|c|c|c|c|c|}
\hline \multirow{2}{*}{\multicolumn{2}{|c|}{ CAE Rev. 2.1. }} & \multirow[t]{2}{*}{1995} & \multirow[t]{2}{*}{1996} & \multirow[t]{2}{*}{1997} & \multirow[t]{2}{*}{1998} & \multirow[t]{2}{*}{1999} & \multirow[t]{2}{*}{2000} & \multirow[t]{2}{*}{2001} & \multirow[t]{2}{*}{2002} & \multirow[t]{2}{*}{2003} & \multirow[t]{2}{*}{2004} & \multirow[t]{2}{*}{2005} & \multirow[t]{2}{*}{2006} & \multicolumn{3}{|c|}{$\begin{array}{c}\text { Diferencial } \\
2006-1995\end{array}$} \\
\hline & & & & & & & & & & & & & & Valor & $\%$ & \\
\hline A & $\begin{array}{l}\text { Agricultura, produção } \\
\text { animal, caça e silvicultura }\end{array}$ & 84 & 21 & 39 & 60 & 95 & 44 & 23 & 17 & 18 & 12 & 11 & 13 & -71 & $-85,0$ & $\nu$ \\
\hline в & Pesca & 510 & 549 & 585 & 487 & 633 & 641 & 1061 & 488 & 430 & 454 & 242 & 313 & -198 & $-38,7$ & $\downarrow$ \\
\hline C & Indústrias extractivas & 742 & 795 & 455 & 381 & 262 & 219 & 108 & 83 & 86 & 91 & 97 & 561 & -181 & $-24,4$ & 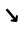 \\
\hline D & Indústrias transformadoras & 84 & 89 & 35 & 88 & 76 & 29 & 104 & 27 & 27 & 22 & 23 & 132 & 49 & 58,0 & $\lambda$ \\
\hline $\mathrm{E}$ & $\begin{array}{l}\text { Produção e distribuição de } \\
\text { electricidade, gás e água }\end{array}$ & 1669 & 1639 & 1621 & 1593 & 1559 & 2948 & 2512 & 2974 & 2736 & 2741 & 2250 & 2047 & 378 & 22,6 & $\lambda$ \\
\hline F & Construção & 55 & 61 & 50 & 48 & 42 & 28 & 35 & 23 & 35 & 30 & 28 & 35 & -20 & $-36,3$ & ע \\
\hline G & $\begin{array}{llr}\text { Comércio } & \text { por grosso e a } \\
\text { retalho; } & \text { reparação } & \text { de } \\
\text { veículos } & \text { automóveis } \\
\text { motociclos } & \text { e de bens } & \text { de } \\
\text { uso pessoal e doméstico }\end{array}$ & 12 & 14 & 16 & 13 & 23 & 22 & 21 & 119 & 18 & 19 & 18 & 21 & 8 & 66,2 & $\lambda$ \\
\hline $\mathbf{H}$ & $\begin{array}{l}\text { Alojamento e restauração } \\
\text { (restaurantes e similares) }\end{array}$ & 13 & 14 & 73 & 26 & 3479 & 28 & 70 & 28 & 18 & 13 & 14 & 14 & 1 & 3,9 & $\pi$ \\
\hline I & $\begin{array}{l}\text { Transportes, armazenagem } \\
\text { e comunicações }\end{array}$ & 578 & 726 & 519 & 948 & 454 & 407 & 363 & 659 & 817 & 295 & 275 & 266 & -312 & $-54,0$ & $\nu$ \\
\hline $\mathrm{J}$ & Actividades financeiras & 466 & 533 & 452 & 547 & 424 & 600 & 692 & 558 & 640 & 868 & 705 & 865 & 398 & 85,4 & $\gamma$ \\
\hline $\mathrm{K}$ & 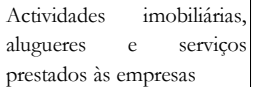 & 55 & 30 & 48 & 83 & 72 & 55 & 25 & 712 & 34 & 50 & 69 & 39 & -17 & $-30,2$ & $\nu$ \\
\hline $\mathbf{L}$ & $\begin{array}{l}\text { Administração pública, } \\
\text { defesa e segurança social }\end{array}$ & 975 & 641 & 739 & 580 & 322 & 299 & 246 & 1430 & 1677 & 1225 & 631 & 536 & -439 & $-45,1$ & $\downarrow$ \\
\hline M & Educação & 87 & 94 & 116 & 428 & 90 & 1050 & 97 & 58 & 70 & 62 & 56 & 57 & -30 & $-34,5$ & 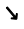 \\
\hline $\mathbf{N}$ & Saúde e ação social & 38 & 38 & 56 & 65 & 53 & 52 & 43 & 4279 & 49 & 48 & 42 & 51 & 12 & 32,5 & $\lambda$ \\
\hline o & $\begin{array}{l}\text { Outras actividades de } \\
\text { serviços colectivos, sociais e } \\
\text { pessoais }\end{array}$ & 187 & 179 & 281 & 159 & 188 & 157 & 107 & 96 & 132 & 86 & 82 & 70 & -116 & $-62,4$ & ע \\
\hline
\end{tabular}

Fonte: Cálculos próprios para os Quadros de Pessoal (GEP/MTSS). 
Em 2006, o sector mais concentrado, destacando-se claramente dos restantes sectores foi a "produção e distribuição de eletricidade, gás e água" (com IHH superior a 1.800, cifrando-se em 2.047), que é aliás um dos sectores tradicionalmente mais concentrados a nível internacional (Borenstein, Bushnell \& Knittel, 1999). Seguem-se sectores onde se considera que a concentração não coloca problemas, dado ser inferior a 1.000, designadamente as "atividades financeiras" (IHH de 865), as "indústrias extrativas" (IHH de 561), a "Administração Pública, defesa e segurança social obrigatória" (IHH de 536), a "pesca" (IHH de 313) e os "Transportes, armazenagens e comunicações" (IHH de 266). Os sectores menos concentrados em 2006 são a "Agricultura, produção animal, caça e silvicultura" (IHH de 13), o "Alojamento e a restauração" (IHH de 14) e o "Comércio por grosso e a retalho; reparação de veículos automóveis motociclos e de bens de uso pessoal e doméstico" (IHH de 21).
A este nível de agregação, os sectores com maiores acréscimos de concentração de empresas entre 1995 e 2006 foram as "J - Atividades financeiras", que permanecem, no entanto, pouco concentradas e a "E - Produção e distribuição de eletricidade, gás e água” que, a partir de 2000, passou a apresentar um elevado grau de concentração industrial. Por outro lado, os sectores que se tornaram mais concorrenciais foram os "I - Transportes, armazenagem e comunicações" e o sector da "B - Pesca"

A preocupação de proporcionar uma maior aderência à realidade conduziu à necessidade de conjugar a análise anterior com uma mais desagregada ao nível dos dois dígitos da CAE, mantendo ainda assim a gestão simples do número de sectores analisados. Na Tabela 2, está patente o índice IHH mais desagregado, agora a 2 dígitos da CAE Rev. 2.1, pois contempla todo o período entre 1995 e 2006.

Tabela 2 - Índices de concentração HHI a 2 dígitos da CAE Rev. 2 e 2.1., entre 1995 e 2006, calculados com base na informação dos Quadros de Pessoal

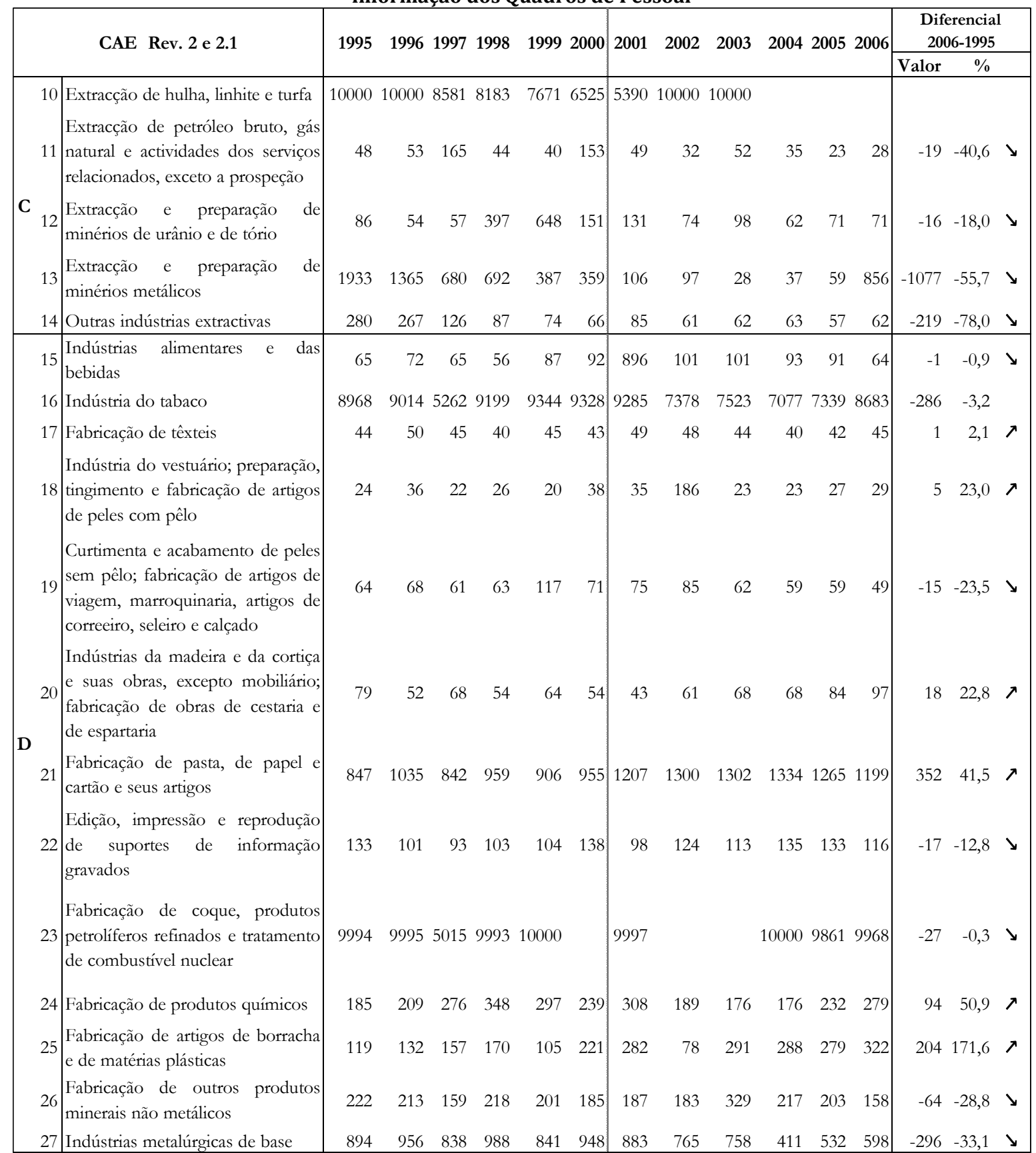


Tabela 2 - Índices de concentração HHI a 2 dígitos da CAE Rev. 2 e 2.1., entre 1995 e 2006, calculados com base na informação dos Quadros de Pessoal (continuação)

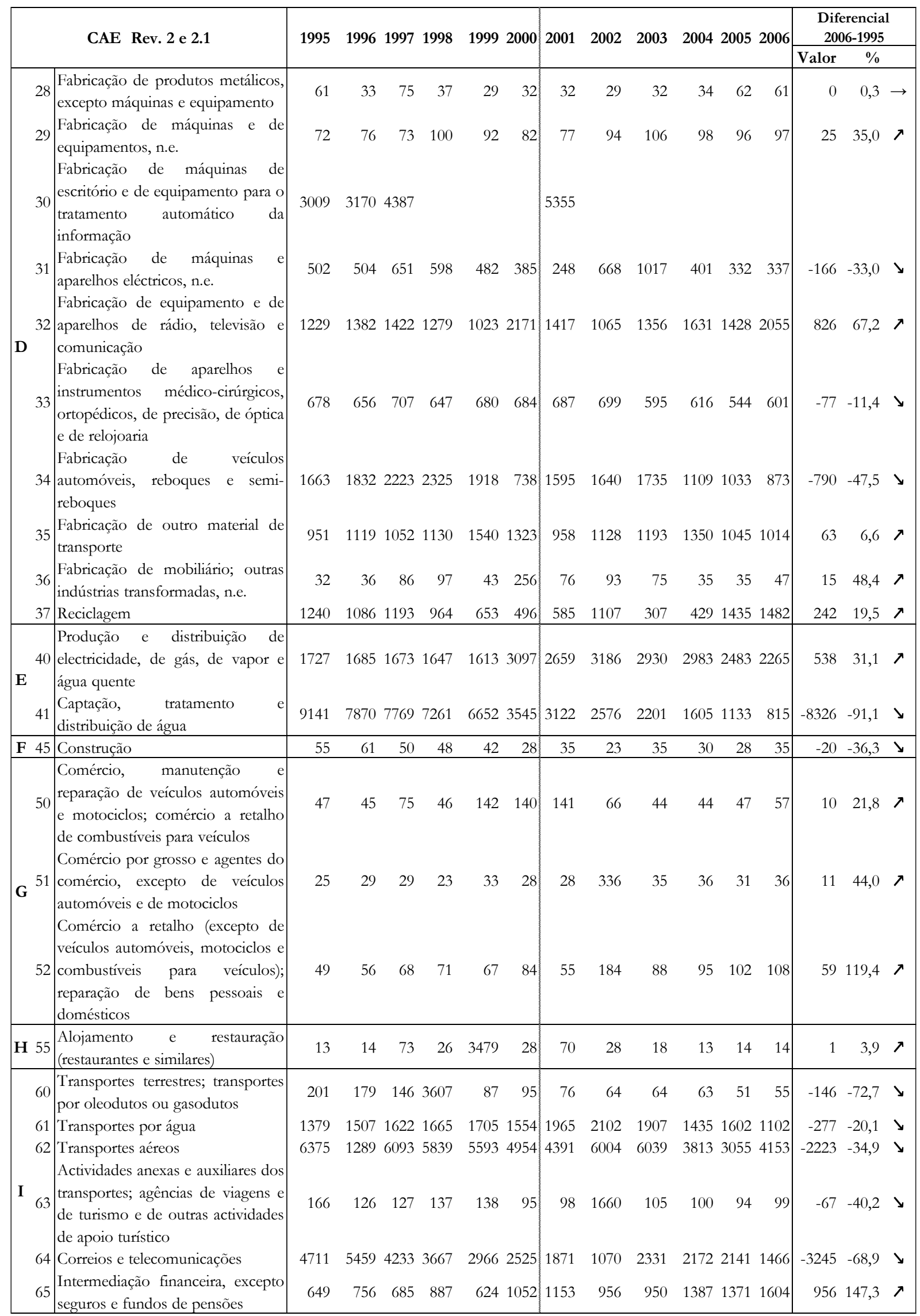


Tabela 2 - Índices de concentração HHI a 2 dígitos da CAE Rev. 2 e 2.1., entre 1995 e 2006, calculados com base na informação dos Quadros de Pessoal (continuação)

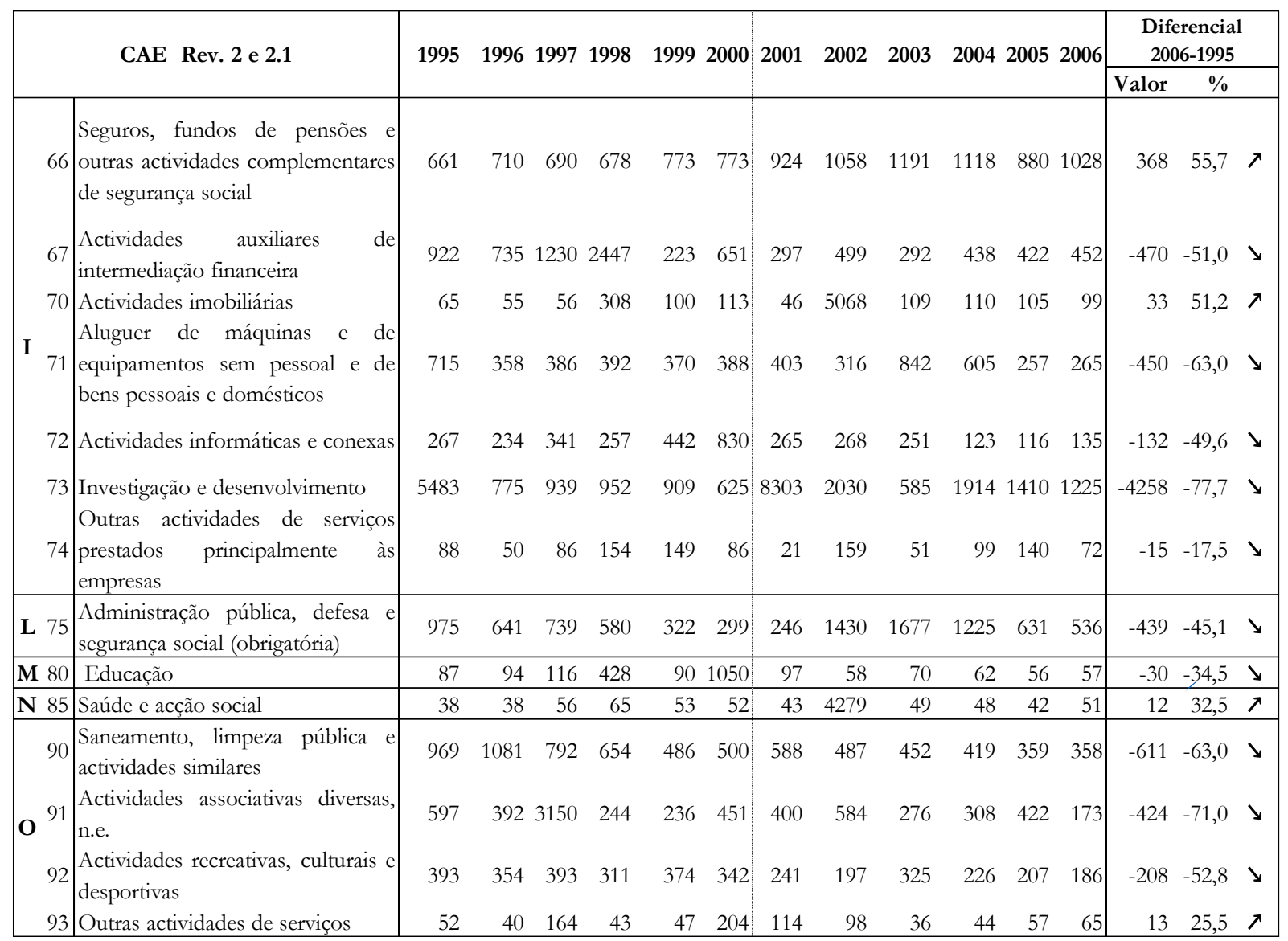

Nota: As células sem valor correspondem a situações em que as empresas deixaram de estar presentes na base de dados, ou por morte ou por terem apresentado um valor de vendas nulo ou ainda por não preencherem os Quadros de Pessoal nesse ano.

Fonte: Cálculos próprios para os Quadros de Pessoal (GEP/MTSS).

Entre 1995 e 2006, Portugal apresenta os mais elevados índices de concentração de empresas no sector do petróleo (CAE 23), do tabaco (CAE 16), no sector de extração de hulha, linhite e turfa (CAE 10), na fabricação de máquinas de escritório e de equipamento para o tratamento automático da informação (CAE 30) e nos transportes aéreos (CAE 40), com níveis de concentração bastante superiores a 1.800, situação semelhante à existente em países como a França, Alemanha, Itália, Japão, Reino Unido e Estados Unidos (OECD, 2006). Habitualmente, os restantes tipos de transportes encontramse bastante menos concentrados, como acontece também no caso de Portugal (CAEs 60 e 61).

A indústria de abastecimento de água (CAE 41), tradicionalmente um dos sectores mais concentrados em vários países europeus, e também em Portugal (IHH de 9.141 em 1995) tem vindo a registar uma diminuição da concentração particularmente evidenciada desde 2000. Crêse que possa estar relacionado com a reestruturação das Águas de Portugal que conduziu à criação de empresas municipais.

A concentração bancária (CAE 81) decresce bastante passando para níveis de concentração inferiores a 1.000 de IHH a partir de 1990. A fabricação de veículos automóveis (CAE 34) e de outro material de transporte (CAE 35) apresentam valores moderadamente concentrados a partir de 1995. No caso particular dos automóveis, a concentração tem vindo a baixar desde 2002. A indústria de reciclagem também se apresenta moderadamente concentrada, com índices de concentração superiores a 1.000 desde 2005, com um diferencial de variação positivo, sugerindo um aumento de concentração entre 1995 e 2006.

Os resultados obtidos e evidenciados nas Tabelas 1 e 2, podem indiciar diferentes tipos de especializações quando comparados a nível internacional com outros países. Por exemplo, a OCDE (OECD, 2006) verifica que existe maior dispersão em Itália no sector dos têxteis e couro do que na Alemanha ou no Reino Unido. No caso de Portugal, também se verifica que existe uma menor concentração em sectores tradicionais como o da fabricação de têxteis (CAE 17), da indústria de vestuário (CAE 18), da curtimenta e acabamento de peles sem pelo (CAE 19) e da indústria da madeira e da cortiça e suas obras (CAE 20), apontando também no sentido de uma maior especialização nestes sectores, dada a dispersão empresarial existente e o predomínio de empresas de pequena e média dimensão. Adicionalmente, os níveis de concentração são habitualmente mais baixos em indústrias que fazem uso intensivo de recursos naturais e primários, como a indústria alimentar e das bebidas, a da madeira e da cortiça e a dos minerais não metálicos primário (com exceção dos dois mencionados anteriormente, como a hulha e o carvão, que, no caso português, apresentam especificidades próprias), dada a necessidade por parte das unidades industriais de se localizarem perto da fonte das matérias-primas.

A este nível de agregação parece existir, genericamente, uma maior concentração na indústria, do que propriamente 
em sectores ligados aos serviços ou à construção. Uma explicação possível é a existência de economias de escala e de uma maior intensidade capitalística na indústria, ligada à necessidade de maiores investimentos, por exemplo em investigação e desenvolvimento. Por outro lado, os serviços estão mais dependentes da sua proximidade ao consumidor final, o que contribui para a sua dispersão geográfica.

\subsection{Sistema de Contas Integrado (INE)}

A Tabela 3 e Tabela 4 apresentam os índices de HerfindahlHirschman entre 2004 e 2006, desagregados a uma letra e a dois e três dígitos da CAE Rev. 2.1, respetivamente, obtidos a partir dos Sistema de Contas Integrado do INE. Os dados são apresentados apenas a partir de 2004 devido à quebra de série verificada nas Estatísticas das Empresas após 2004.

Tabela 3 - Índices de concentração IHH a 1 Letra da CAE Rev. 2.1, entre 2004 e 2006, calculados com base na informação do SCIE do INE

\begin{tabular}{|c|c|c|c|c|c|c|c|}
\hline \multicolumn{2}{|r|}{ CAE Rev. 2.1. } & \multirow{2}{*}{2004} & \multirow{2}{*}{2005} & \multirow{2}{*}{2006} & \multicolumn{3}{|c|}{ Diferencial 2006-2004 } \\
\hline & & & & & Valor & $\%$ & \\
\hline \multicolumn{2}{|r|}{ C-K } & 13 & 15 & 18 & 5 & 42,5 & \\
\hline & Indústrias extractivas & 236 & 519 & 1023 & 788 & 334,1 & \\
\hline $\mathbf{D}$ & Indústrias transformadoras & 92 & 119 & 141 & 49 & 52,6 & \\
\hline $\mathbf{E}$ & Produção e distribuição de electricidade, gás e água & 1962 & 1846 & 1861 & -101 & $-5,2$ & \\
\hline $\mathbf{F}$ & Construção & 26 & 24 & 21 & -5 & $-20,3$ & \\
\hline G & $\begin{array}{l}\text { Comércio por grosso e a retalho; reparação de veículos } \\
\text { automóveis motociclos e de bens de uso pessoal e doméstico }\end{array}$ & 14 & 16 & 17 & 2 & 14,2 & \\
\hline $\mathbf{H}$ & Alojamento e restauração (restaurantes e similares) & 10 & 10 & 10 & -1 & $-6,6$ & \\
\hline $\mathbf{I}$ & Transportes, armazenagem e comunicações & 230 & 213 & 197 & -32 & $-14,1$ & \\
\hline $\mathbf{J}$ & Actividades financeiras & 379 & 424 & 446 & 67 & 17,7 & \\
\hline $\mathbf{K}$ & $\begin{array}{l}\text { Actividades imobiliárias, alugueres e serviços prestados às } \\
\text { empresas }\end{array}$ & 12 & 14 & 11 & -1 & $-6,4$ & \\
\hline $\mathbf{M}$ & Educação & 33 & 29 & 29 & -4 & $-12,2$ & \\
\hline $\mathbf{N}$ & Saúde e ação social & 50 & 57 & 75 & 25 & 50,2 & \\
\hline $\mathbf{O}$ & Outras actividades de serviços colectivos, sociais e pessoais & 76 & 66 & 65 & -10 & $-13,8$ & \\
\hline
\end{tabular}

Fonte: INE, com base no SCIE e na metodologia do Eurostat e OECD (2007).

Tabela 4 - Índices de concentração IHH a 2 e 3 dígitos da CAE Rev. 2.1, entre 2004 e 2006, calculados com base na informação do SCIE do INE

\begin{tabular}{|c|c|c|c|c|c|c|c|c|}
\hline \multirow{2}{*}{\multicolumn{2}{|c|}{$\begin{array}{c}\text { CAE } \\
\text { Rev. 2.1. }\end{array}$}} & \multirow{2}{*}{ Descritivo } & \multirow{2}{*}{2004} & \multirow{2}{*}{2005} & \multirow{2}{*}{2006} & \multicolumn{3}{|c|}{ Diferencial 2007-2004 } \\
\hline & & & & & & Valor & $\%$ & \\
\hline $\mathbf{C}$ & $13-14$ & 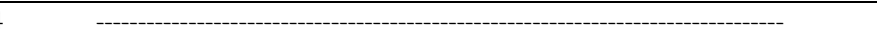 & 237 & 519 & 1023 & 786 & 331,0 & \\
\hline \multirow{14}{*}{$\mathbf{D}$} & $15-16$ & 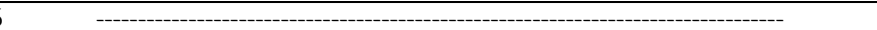 & 92 & 92 & 89 & -3 & -3.1 & 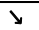 \\
\hline & $17-18$ & - & 17 & 17 & 19 & 2 & 13,1 & $\nearrow$ \\
\hline & & Curtimenta e acabamento de peles sem pêlo; fabricação de artigos de viagem, & 52 & 48 & 50 & -3 & $-5,6$ & $\searrow$ \\
\hline & 20 & $\begin{array}{l}\text { Indústrias da madeira e da cortiça e suas obras, excepto mobiliário; } \\
\text { fabricação de obras de cestaria e de espartaria }\end{array}$ & 93 & 104 & 125 & 32 & 34,3 & $\nearrow$ \\
\hline & $21-22$ & - & 274 & 267 & 298 & 24 & 8,7 & $\nearrow$ \\
\hline & 23 & $\begin{array}{l}\text { Fabricação de coque, produtos petrolíferos refinados e tratamento de } \\
\text { combustível nuclear }\end{array}$ & 10000 & 10000 & 10000 & 0 & 0,0 & $\rightarrow$ \\
\hline & & Fabricação de produtos químicos & 268 & 263 & 264 & -4 & $-1,6$ & $\searrow$ \\
\hline & & Fabricação de artigos de borracha e de matérias plásticas & 282 & 252 & 314 & 32 & 11,4 & $\lambda$ \\
\hline & & Fabricação de outros produtos minerais não metálicos & 141 & 141 & 139 & -2 & $-1,4$ & $\searrow$ \\
\hline & $27-28$ & & 119 & 65 & 80 & -39 & $-32,9$ & 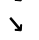 \\
\hline & & Fabricação de máquinas e de equipamentos, n.e. & 82 & 86 & 97 & 14 & 17,5 & $\nearrow$ \\
\hline & $30-33$ & & 482 & 560 & 531 & 50 & 10,3 & $\nearrow$ \\
\hline & $34-35$ & 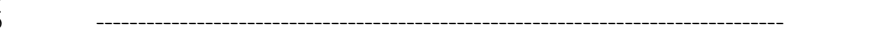 & 998 & 804 & 952 & -46 & -46 & 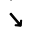 \\
\hline & $36-37$ & 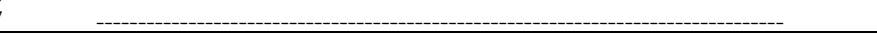 & 123 & 99 & 89 & -34 & $-27,4$ & 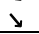 \\
\hline $\mathbf{E}$ & 40 & Produção e distribuição de electricidade, de gás, de vapor e água quente & 2323 & 2159 & 2152 & -171 & $-7,4$ & 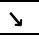 \\
\hline \multirow{2}{*}{$\mathbf{F}$} & & Captação, tratamento e distribuição de água & 490 & 430 & 419 & -71 & $-14,5$ & 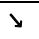 \\
\hline & & Construção & 26 & 24 & 21 & -5 & $-20,3$ & $\searrow$ \\
\hline \multirow{9}{*}{ G } & & $\begin{array}{l}\text { Comércio, manutenção e reparação de veículos automóveis e motociclos; } \\
\text { comércio a retalho de combustíveis para veículos }\end{array}$ & 52 & 56 & 46 & -6 & $-11,9$ & $\searrow$ \\
\hline & 51 & $\begin{array}{l}\text { Comércio por grosso e agentes do comércio, excepto de veículos automóveis } \\
\text { e de motociclos }\end{array}$ & 23 & 25 & 26 & 4 & 15,7 & $\nearrow$ \\
\hline & 52 & $\begin{array}{l}\text { Comércio a retalho (excepto de veículos automóveis, motociclos e } \\
\text { combustíveis para veículos); reparação de bens pessoais e domésticos }\end{array}$ & 80 & 85 & 92 & 12 & 14,7 & $\pi$ \\
\hline & & Comércio a retalho em estabelecimentos não especializados & 582 & 594 & 602 & 20 & 3,5 & $\nearrow$ \\
\hline & 522 & $\begin{array}{l}\text { Comércio a retalho de produtos alimentares, bebidas e tabaco, em } \\
\text { estabelecimentos especializados }\end{array}$ & 4 & 4 & 4 & 0 & 13,4 & $\pi$ \\
\hline & 523 & Comércio a retalho de produtos farmacêuticos, médicos, cosméticos e de & 9 & 11 & 12 & 3 & 34,6 & $\lambda$ \\
\hline & 524 & $\begin{array}{l}\text { Comércio a retalho de outros produtos novos em estabelecimentos } \\
\text { especializados }\end{array}$ & 407 & 371 & 543 & 136 & 33,6 & $\nearrow$ \\
\hline & 525 & $\begin{array}{l}\text { Comércio a retalho de artigos em segunda mão em estabelecimentos } \\
\text { especializados }\end{array}$ & 119 & 105 & 99 & -20 & $-17,1$ & $\searrow$ \\
\hline & 526 & Comércio a retalho não efectuado em estabelecimentos & 27 & 33 & 35 & 8 & 30,1 & $\lambda$ \\
\hline
\end{tabular}


Tabela 4 - Índices de concentração IHH a 2 e 3 dígitos da CAE Rev. 2.1, entre 2004 e 2006, calculados com base na informação do SCIE do INE (continuação)

\begin{tabular}{|c|c|c|c|c|c|c|c|}
\hline \multirow{3}{*}{$\mathbf{H}$} & 55 Alojamento e restauração (restaurantes e similares) & 10 & 10 & 10 & -1 & $-6,6$ & 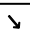 \\
\hline & 551 Estabelecimentos hoteleiros & 49 & 48 & 48 & -1 & $-1,4$ & $\checkmark$ \\
\hline & 552 Parques de campismo e outros locais de alojamento de curta duração & 13 & 12 & 12 & -1 & $-8,3$ & 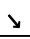 \\
\hline \multirow{7}{*}{ I } & 60 Transportes terrestres; transportes por oleodutos ou gasodutos & 168 & 236 & 304 & 136 & 81,0 & $\pi$ \\
\hline & 61 Transportes por água & 1111 & 806 & 779 & -332 & $-29,9$ & $y$ \\
\hline & 62 Transportes aéreos & 3126 & 3221 & 3367 & 241 & 7,7 & $\lambda$ \\
\hline & $\begin{array}{l}63 \text { Actividades anexas e auxiliares dos transportes; agências de viagens e de } \\
\text { turismo e de outras actividades de apoio turístico }\end{array}$ & 134 & 126 & 133 & -1 & $-0,7$ & 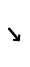 \\
\hline & 64 Correios e telecomunicações & 1430 & 1364 & 1307 & -124 & $-8,7$ & $\checkmark$ \\
\hline & 641 Actividades dos correios & 5033 & 4877 & 5008 & -25 & $-0,5$ & 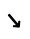 \\
\hline & 642 Telecomunicações & 1715 & 1642 & 1567 & -148 & $-8,6$ & 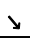 \\
\hline \multirow{3}{*}{$\mathbf{J}$} & 65 Intermediação financeira, excepto seguros e fundos de pensões & 847 & 871 & 882 & 35 & 4,2 & $\pi$ \\
\hline & $66 \begin{array}{l}\text { Seguros, fundos de pensões e outras actividades complementares de } \\
\text { segurança social }\end{array}$ & 806 & 912 & 828 & 22 & 2,7 & $\pi$ \\
\hline & 67 Actividades auxiliares de intermediação financeira & 193 & 131 & 180 & -14 & $-7,1$ & 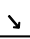 \\
\hline \multirow{8}{*}{$\mathbf{K}$} & 70 Actividades imobiliárias & 39 & 32 & 31 & -8 & $-20,3$ & $y$ \\
\hline & $\begin{array}{l}71 \text { Aluguer de máquinas e de equipamentos sem pessoal e de bens pessoais e } \\
\text { domésticos }\end{array}$ & 198 & 174 & 186 & -13 & $-6,5$ & 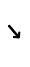 \\
\hline & 72 Actividades informáticas e conexas & 93 & 99 & 210 & 117 & 125,2 & $\nearrow$ \\
\hline & 73 Investigação e desenvolvimento & 201 & 239 & 220 & 18 & 9,0 & $\nearrow$ \\
\hline & $\begin{array}{l}74 \text { Outras actividades de serviços prestados principalmente às empresas } \\
\text { Actividades jurídicas, de contabilidade e de auditoria; consultoria fiscal; }\end{array}$ & 23 & 30 & 19 & -4 & $-19,3$ & 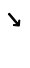 \\
\hline & $\begin{array}{l}741 \text { estudos de mercado e sondagens de opinião; consultoria empresarial e de } \\
\text { gestão; gestão de sociedades de participacões sociais }\end{array}$ & 64 & 112 & 52 & -11 & $-18,0$ & 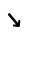 \\
\hline & 742 Actividades de arquitectura, de engenharia e técnicas afins & 108 & 119 & 39 & -69 & $-64,0$ & $\checkmark$ \\
\hline & 743 Actividades de ensaios e análises técnicas & 242 & 213 & 227 & -14 & $-6,0$ & 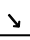 \\
\hline $\mathbf{M}$ & 80 Educação & 33 & 29 & 29 & -4 & $-12,2$ & 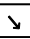 \\
\hline $\mathbf{N}$ & 85 Saúde e acção social & 50 & 57 & 75 & 25 & 50,2 & $\lambda$ \\
\hline \multirow{3}{*}{$\mathbf{O}$} & 90 Saneamento, limpeza pública e actividades similares & 227 & 212 & 187 & -40 & $-17,7$ & 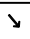 \\
\hline & 92 Actividades recreativas, culturais e desportivas & 173 & 157 & 165 & -9 & $-4,9$ & 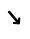 \\
\hline & 93 Outras actividades de serviços & 37 & 37 & 25 & -13 & $-34,3$ & $\searrow$ \\
\hline
\end{tabular}

Fonte: INE, com base no SCIE e na metodologia do Eurostat e OECD (2007).

Em 2006, regista-se uma elevada concentração nos seguintes sectores, "CAE 23 - Fabricação de coque, produtos petrolíferos refinados e tratamento de combustível nuclear" e "CAE 641 - Atividades dos correios", "CAE 62 Transportes aéreos". No que se refere aos sectores moderadamente concentrados há a registar a CAE 13-14 correspondente à "Extração e preparação de minérios metálicos" e "Outras indústrias extrativas", a "CAE 40 Produção e distribuição de eletricidade, de gás, de vapor e água quente" e o agregado correspondente à "CAE 64 Correios e Telecomunicações") particularmente o das Telecomunicações (CAE 642).

Os sectores que registaram maiores acréscimos de concentração entre 2004 e 2006 são os "Transportes Aéreos" (CAE 62), um sector em geral altamente concentrado, e outras atividades não concentradas como as "Atividades informáticas e conexas" (CAE 72), a "Intermediação financeira, exceto seguros e fundos de pensões" (CAE 65) e os "Seguros fundos de pensões e outras atividades complementares de segurança social" (CAE 66). 0 que registou o maior decréscimo foi o sector altamente concentrado da "Produção e distribuição de eletricidade, de gás, de vapor e água quente" (CAE 40)

A comparação entre as duas fontes de informação apresentadas, os Quadros de Pessoal e o Sistema de Contas Integrado das Empresas, apresenta-se nas Tabela 5 e Tabela 6, respetivamente. Para o SCIE são apresentados dados comparativos com os Quadros de Pessoal (Tabela 6) que se referem aos três anos para os quais se disponibiliza informação, neste trabalho. Na Tabela 5, e por os Quadros de Pessoal incluirem os resultados obtidos num período mais longo de 11 anos consecutivos, são apresentados os resultados dos três anos em que é possível realizar a comparação com o SCIE (2004 a 2006) tendo sido selecionados dois anos anteriores ao período (1995 e 2000) - a inclusão destes dois anos permite analisar a evolução da concentração por setores até 2004. 
Tabela 5 - Resumo dos sectores altamente e moderadamente concentrados por CAE, segundo os Quadros de Pessoal

\begin{tabular}{|c|c|c|c|}
\hline \multicolumn{4}{|c|}{ Anos } \\
\hline & 1995 & 2000 & 2004 \\
\hline \multicolumn{2}{|c|}{$\begin{array}{l}10 \text { - Extracção de hulha, linhite e turfa } \\
16 \text {-Indústria do tabaco } \\
23 \text { - Fabr. de coque, prod. petrolíferos } \\
\text { refinados e trat. combustível nuclear. }\end{array}$} & $\begin{array}{l}10 \text { - Extracção de hulha, linhite e } \\
\text { turfa } \\
16 \text { - Indústria do tabaco } \\
32 \text { - Fabr. de equip. e de aparelhos } \\
\text { de rádio, televisão e comunicação } \\
40 \text { - Produção e distribuição de } \\
\text { electricidade, de gás, de vapor e } \\
\text { água quente. } \\
41 \text { - Captação, tratamento e } \\
\text { distribuição de água } \\
62 \text { - Transportes aéreos } \\
64 \text { - Correios e telecomunicações }\end{array}$ & $\begin{array}{l}16 \text { - Indústria do tabaco } \\
23 \text { - Fabr. de coque, prod. } \\
\text { petrolíferos refinados e trat. } \\
\text { combustível nuclear } \\
\mathbf{4 0} \text { - Produção e distribuição de } \\
\text { electricidade, de gás, de vapor } \\
\text { e água quente. } \\
\mathbf{6 2} \text { - Transportes aéreos } \\
64 \text { - Correios e telecomunicações } \\
73 \text { - Investigação e } \\
\text { desenvolvimento }\end{array}$ \\
\hline \multicolumn{2}{|c|}{$\begin{array}{l}13 \text { - Extracção e preparação de minérios } \\
\text { metálicos } 30 \text {-Fabr. máq. de escrit. e de equip. } \\
\text { p/ trat. autom. Informação } \\
32 \text {-Fabr. de equip. e de aparelhos de rádio, } \\
\text { televisão e comunicação } \\
34 \text { - Fabr. de veículos automóveis, reboques e } \\
\text { semi-reboques } \\
37 \text { - Reciclagem } \\
40 \text { - Produção e distribuição de electricidade, } \\
\text { de gás, de vapor e água quente } \\
41 \text { - Captação, tratamento e distribuição de } \\
\text { água } \\
61 \text {-Transportes por água } \\
62 \text { - Transportes aéreos } \\
64 \text {-Correios e telecomunicações } \\
73 \text { - Investigação e desenvolvimento }\end{array}$} & $\begin{array}{l}35 \text { - Fabricação de outro material } \\
\text { de transporte } \\
61 \text { - Transportes por água } \\
65 \text { - Intermediação financeira, } \\
\text { exc. seguros e fundos de pensões } \\
80 \text { - Educação }\end{array}$ & $\begin{array}{l}21 \text { - Fabric. de pasta, de papel e } \\
\text { cartão e seus artigos } \\
32 \text { - Fabr. de equip. e de } \\
\text { aparelhos de rádio, televisão e } \\
\text { comunicação } \\
34 \text { - Fabr. de veículos automóveis, } \\
\text { reboques e semi-reboques } \\
35 \text { - Fabricação de outro material } \\
\text { de transporte } \\
41 \text { - Captação, tratamento e } \\
\text { distribuição de água } \\
61 \text { - Transportes por água } \\
65 \text { - Intermediação financeira, } \\
\text { exc. seguros e fundos de pensões } \\
66 \text { - Seguros, fundos de pensões e } \\
\text { outras activ. compl. de seg.social } \\
75 \text { - Administração Pública, } \\
\text { defesa e segurança social } \\
\text { «obrigatória» }\end{array}$ \\
\hline \multirow{2}{*}{ Setores } & \multicolumn{3}{|c|}{ Anos } \\
\hline & \multicolumn{2}{|c|}{2005} & 2006 \\
\hline 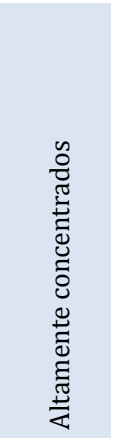 & \multicolumn{2}{|c|}{$\begin{array}{l}23 \text { - Fabr. de coque, prod. petrolíferos refinados e trat. } \\
\text { combustível nuclear } \\
16 \text { - Indústria do tabaco } \\
62 \text { - Transportes aéreos } \\
64 \text { - Correios e telecomunicações } \\
40 \text { - Produção e distribuição de electricidade, de gás, de vapor e } \\
\text { água quente }\end{array}$} & $\begin{array}{l}10 \text { - Extracção de hulha, linhite e turfa } \\
16 \text { - Indústria do tabaco } \\
23 \text { - Fabr. de coque, prod. } \\
\text { petrolíferos refinados e trat. } \\
\text { combustível nuclear } \\
32 \text { - Fabr. de equip. e de aparelhos de } \\
\text { rádio, televisão e comunicação } \\
40 \text { - Produção e distribuição de } \\
\text { electricidade, de gás, de vapor e água } \\
\text { quente } \\
62 \text { - Transportes aéreos }\end{array}$ \\
\hline 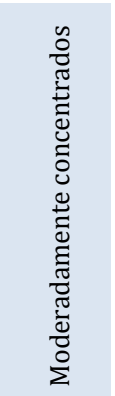 & \multicolumn{2}{|c|}{$\begin{array}{l}21 \text { - Fabric. de pasta, de papel e cartão e seus artigos } \\
32 \text { - Fabr. de equip. e de aparelhos de rádio, televisão e comunicação } \\
34 \text { - Fabr. de veículos automóveis, reboques e semi-reboques } \\
35 \text { - Fabricação de outro material de transporte } \\
37 \text { - Reciclagem } \\
41 \text { - Captação, tratamento e distribuição de água } \\
61 \text { - Transportes por água } \\
65 \text { - Intermediação financeira, exc. seguros e fundos de pensões } \\
73 \text { - Investigação e desenvolvimento }\end{array}$} & $\begin{array}{l}21 \text { - Fabric. de pasta, de papel e cartão e } \\
\text { seus artigos } \\
35 \text { - Fabricação de outro material de } \\
\text { transporte } \\
37 \text { - Reciclagem } \\
61 \text { - Transportes por água } \\
64 \text { - Correios e telecomunicações } \\
65 \text { - Intermediação financeira, exc. } \\
\text { seguros e fundos de pensões } \\
66 \text { - Seguros, fundos de pensões e } \\
\text { outras activ. compl. de seg.social } \\
73 \text { - Investigação e desenvolvimento }\end{array}$ \\
\hline
\end{tabular}

Nota: A negrito encontram-se destacados os sectores em comum nas duas fontes de informação.

Fonte: Dados do INE provenientes do Sistema de Contas Integrado das Empresas (SCIE) e cálculos próprios para os Quadros de Pessoal (GEP/MTSS). 
Tabela 6 - Resumo dos sectores altamente e moderadamente concentrados por CAE, segundo o SCIE

\begin{tabular}{|c|c|c|c|}
\hline \multirow{2}{*}{ Setores } & \multicolumn{3}{|c|}{ Anos } \\
\hline & 2004 & 2005 & 2006 \\
\hline 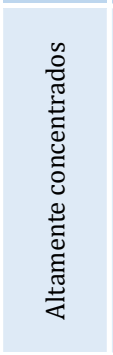 & $\begin{array}{l}23 \text { - Fabr. de coque, prod. } \\
\text { petrolíferos refinados e } \\
\text { trat. combustível nuclear } \\
40 \text { - Produção e } \\
\text { distribuição de } \\
\text { electricidade, de gás, de } \\
\text { vapor e água quente } \\
62 \text { - Transportes aéreos }\end{array}$ & $\begin{array}{l}23 \text { - Fabr. de coque, prod. petrolíferos } \\
\text { refinados e trat. combustível nuclear } \\
62 \text { - Transportes aéreos } \\
641 \text { - Actividades dos correios } \\
\mathbf{4 0} \text { - Produção e distribuição de } \\
\text { electricidade, de gás, de vapor e água } \\
\text { quente } \\
723 \text { - Processamento de dados } \\
724 \text { - Actividades de bancos de dados e } \\
\text { disponibilização de informação em } \\
\text { contínuo }\end{array}$ & $\begin{array}{l}23 \text { - Fabr. de coque, prod. petrolíferos } \\
\text { refinados e trat. combustível nuclear } \\
\mathbf{4 0} \text { - Produção e distribuição de } \\
\text { electricidade, de gás, de vapor e água } \\
\text { quente } \\
\mathbf{6 2} \text { - Transportes aéreos } \\
641 \text { - Actividades dos Correios } \\
721 \text { - Consultoria em equipamento } \\
\text { informáticos } \\
724 \text { - Actividades de bancos de dados e } \\
\text { disponibilização de informação em contí }\end{array}$ \\
\hline 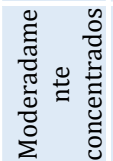 & $\begin{array}{l}61 \text { - Transportes por } \\
\text { água } \\
64 \text { - Correios e } \\
\text { telecomunicações }\end{array}$ & $\begin{array}{l}62 \text { - Transportes aéreos } \\
64 \text { - Correios e telecomunicações } \\
642 \text { - Telecomunicações }\end{array}$ & $\begin{array}{l}64 \text { - Correios e telecomunicações } \\
642 \text { - Telecomunicações } \\
13 \text { - Extracção e preparação de minérios } \\
\text { metálicos } \\
14 \text { - Outras indústrias extractivas }\end{array}$ \\
\hline
\end{tabular}

Notas: A negrito encontram-se destacados os sectores em comum nas duas fontes de informação. Nesta fonte de informação encontra-se disponível um nível de desagregação superior, a três dígitos da CAE.

Fonte: Dados do INE provenientes do Sistema de Contas Integrado das Empresas (SCIE) e cálculos próprios para os Quadros de Pessoal (GEP/MTSS).

As Tabelas 5 e 6 revelam que, em 2004 e 2006, os sectores de mais elevada concentração, comuns a estas duas fontes de informação, são a "Fabricação de coque, produtos petrolíferos refinados (...)", referente à CAE 23, a "Produção, distribuição de eletricidade (...)" (CAE 40) e os "Transportes Aéreos" (CAE 62). Entre os moderadamente concentrados está, em 2006, o sector referente à "CAE 61 - Transportes por água" e, em 2004, os "Correios e as Telecomunicações" (CAE 64). Entre os sectores mais dispersos está o sector da Construção (CAE 45), ao nível das duas fontes de informação, em linha com a evidência existente para diversos países e regiões (Ruiz-Valenzuela, Moreno-Serrano \& Vayá-Valcarce, 2007; OECD, 2006). Também nesta classificação se incluem serviços não intensivos em conhecimento, como os referentes ao "Alojamento e restauração" (CAE 55), ao "Comércio por grosso (...) (CAE 51), "Comércio, manutenção e reparação de veículos automóveis (...)" (CAE 50), "Comércio a retalho" (CAE 52) e "Outras atividades de serviços" (CAE 93). Outro aspeto interessante é que nos Quadros de Pessoal também estão entre os sectores menos concentrados, sectores intensivos em conhecimento como o referente à "CAE 80 - Educação") e à "CAE 85 - Saúde e Ação Social". Nos Quadros de Pessoal, os sectores da Administração Pública estão subrepresentados, pelo que estes valores devem ser interpretados cautelosamente.

Os Quadros de Pessoal apontam, ao nível dos serviços intensivos em conhecimento (os denominados KIBS ou Knowledge Intensive Business Services, que compreendem as CAEs 72 a 74) para uma maior concentração no sector abrangido pela "CAE 73 - Investigação e Desenvolvimento", relativamente aos sectores referentes à "CAE 72 Atividades informáticas e conexas" e "CAE 74 - Outras atividades de serviços prestadas principalmente às empresas", embora os valores para a generalidade dos anos não demonstrem uma elevada concentração. No caso dos dados do SCIE, é também o sector correspondente à CAE 73 que apresenta maiores valores, ainda que os índices sejam inferiores aos dos Quadros de Pessoal. No entanto, a um nível mais desagregado, constata-se que dentro da "CAE 72
- Atividades informáticas e conexas", nomeadamente no setor referente à "CAE 721 - Consultoria em equipamento informático" e "CAE 724 - Atividades de bancos de dados (...)", em 2006, o nível de concentração é superior a 1.800 . Este tipo de serviços, a sua evolução ao longo dos últimos anos e o respetivo impacto na economia portuguesa não têm sido suficientemente estudados, demonstrando, os resultados deste trabalho, que é pertinente um melhor conhecimento de um setor caraterizado por pequenas empresas inovadoras com uma intensidade de crescimento elevada e superior à dos restantes setores (Carvalho \& Pinto, 2013)

\section{Conclusão}

Os índices de concentração são utilizados frequentemente como inputs para a definição de regras de política pública e de medidas relativamente à estrutura de mercado a nível sectorial. 0 cálculo dos índices de Herfindahl-Hirschman para Portugal entre 1995 e 2006 permite efetuar uma análise de sensibilidade, através de uma comparação relativa do grau de concentração entre diferentes sectores no domínio agrícola, industrial, da construção e dos serviços e ponderar sobre a sua evolução num período de 11 anos.

A comparação entre duas fontes de informação, os Quadros de Pessoal do Ministério do Trabalho e da Solidariedade Social e do Sistema Integrado de Contas do Instituto Nacional de Estatística, consideradas as principais e as mais exaustivas sobre o tecido empresarial português, às quais foi aplicada a mesma metodologia de harmonização, permite extrair conclusões mais sólidas. Existem no entanto divergências naturais, centradas essencialmente nas características destas duas fontes de informação. Os Quadros de Pessoal evidenciam um conjunto mais vasto de sectores com elevada concentração, comparativamente aos resultados obtidos a partir do Sistema Integrado de Contas do INE. Isto pode estar relacionado com o próprio universo das duas fontes de informação. Enquanto o SCIE apresenta um universo mais alargado de empresas, onde se incluem mais tipologias empresariais, os Quadros de Pessoal 
consideram um conjunto distinto de empresas, mais restrito em número, compreendendo apenas as empresas com pelo menos um trabalhador inscrito na Segurança Social, o que se considera poder sub-representar determinados sectores económicos face aos dados do SCIE.

A evidência que resulta da análise das duas fontes de informação revela que em 2004 e 2006, os sectores de mais elevada concentração são a "Fabricação de coque, produtos petrolíferos refinados e tratamento de combustível nuclear", a "Produção, distribuição de eletricidade" e os "Transportes Aéreos", à semelhança do que acontece em vários países europeus e nos Estados Unidos. Entre os moderadamente concentrados estão, em 2006, o sector dos "Transportes por água" e em 2004 os "Correios e as Telecomunicações". É de salientar que a literatura mais ligada à Organização Industrial tem verificado que fenómenos como a atividade de multinacionais têm contribuído para aumentos de concentração, em particular na indústria e para alterações na sua distribuição regional em diversos países (ver, por exemplo, Barbosa \& Eiriz (2011) para o caso português).

Entre os sectores mais dispersos estão designadamente o sector da Construção e serviços não intensivos em conhecimento, como os referentes ao "Alojamento e restauração", ao "Comércio por grosso", "Comércio, manutenção e reparação de veículos automóveis", "Comércio a retalho" e "Outras atividades de serviços". Sectores tradicionais, como o têxtil, vestuário e a indústria da madeira e da cortiça também se encontram bastante dispersos. As indústrias extrativas registaram o segundo maior acréscimo de IHH neste período.

Para além das atividades anteriormente mencionadas, obtidas através da análise das duas fontes de informação, os Quadros de Pessoal apresentam um conjunto adicional de sectores altamente concentrados. Destacam-se, em 2006, designadamente os sectores da "Extração de hulha, linhite e turfa", da "Indústria do tabaco" e da "Fabricação de equipamento e de aparelhos de rádio, televisão e comunicação", bem como de sectores moderadamente concentrados, como a "Fabricação de pasta de papel e cartão e seus artigos", "Fabricação de outro material de transporte", "Reciclagem", "Transportes por água", "Intermediação financeira, exceto seguros e fundos de pensões", "Seguros, fundos de pensões e outras atividades complementares de segurança social" e a própria "Investigação e desenvolvimento". Os dados referentes ao ano de 2006, provenientes do Sistema Integrado de Contas, apresentam ainda os sectores de "extração e preparação de minérios metálicos" e de "outras indústrias extrativas" como moderadamente concentrados. As desagregações possibilitadas pelos dados do SCIE permitem aferir mais concretamente quais são as atividades de elevada concentração, nomeadamente no que diz respeito aos serviços ("Atividades dos correios, "Consultoria em equipamento informático", "Atividades de bancos de dados e disponibilização de informação em contínuo").

Os Quadros de Pessoal apontam para, no caso dos serviços intensivos em conhecimento, uma maior concentração no sector "Investigação e Desenvolvimento", designadamente nos sectores "Atividades informáticas e conexas" e "Outras atividades de serviços prestadas principalmente às empresas", embora os valores para a generalidade dos anos não demonstrem uma elevada concentração. No caso dos dados do SCIE, é também o sector da investigação e do desenvolvimento que apresenta maior concentração, ainda que os índices sejam inferiores aos calculados através dos Quadros de Pessoal. No entanto, a um nível mais desagregado, constata-se que no sector "Atividades informáticas e conexas", nomeadamente nas "Atividades de bancos de dados" em 2006 e na "Consultoria em equipamento informático", em 2006, o nível de concentração é elevado. Quanto à intensidade tecnológica, os serviços apresentam um comportamento dual. Os serviços intensivos em conhecimento apresentam-se mais concentrados do que os serviços menos intensivos em conhecimento. Este fenómeno não é tão evidente na indústria a partir da desagregação fornecida. A emergência da economia do conhecimento tem vindo a intensificar algumas dessas características (no caso por exemplo de externalidades associadas com a investigação e o desenvolvimento e com o capital humano, das vantagens comparativas internas às empresas, bem como com fatores associados com a criação de novos bens (Carvalho \& Pinto, 2013)), que por sua vez têm vindo a gerar um aumento de concentração.

Finalmente, duas últimas notas reconhecendo a limitação destes resultados. A primeira limitação deste trabalho de investigação, que se assume meramente descritivo, é o facto de fazer uso de uma única medida de concentração, o IHH. Tal limitação pode prestar-se a eventuais disparidades de resultados quando forem utilizados índices de concentração diferentes ou outras formulações para a aferição da concentração. Esta aferição só poderá ser realizada em trabalho de investigação futuro que permita comparar os resultados agora apresentados com outros obtidos por diferentes medidas de concentração sugeridas na literatura. A segunda limitação do estudo, refere-se ao período de estudo - o período de 11 anos, entre 1995 e 2006, em que foi utilizada a Rev. 2.1. da classificação das atividades económicas. De facto, a análise de um período em que os dados se podem comparar mais directamente em períodos temporais e com classificações coincidentes, poderá vir a ocorrer em futuras linhas de investigação. Passados cerca de oito anos desde a entrada em vigor da nova revisão da classificação das atividades económicas, e após um período de mudanças estruturais em várias atividades económicas, será possível de forma mais consistente, verificar e comparar com os resultados agora apresentados a evolução da concentração sectorial na economia portuguesa.

\section{Agradecimentos}

As autoras gostariam de agradecer ao Gabinete de Estratégia e Planeamento do Ministério do Trabalho e da Solidariedade Social o fornecimento da base de dados dos Quadros de Pessoal e ao Instituto Nacional de Estatística pelo fornecimento dos índices Herfindahl-Hirschman. Este trabalho reflete apenas as opiniões dos seus autores e não de nenhuma entidade oficial. Eventuais erros e omissões são da nossa única responsabilidade.

\section{Referências}

Adelman, M. A. (1951). The measurement of industrial concentration. Review of Economics and Statistics, 33(4), 269-296. 
Amador, J. \& Soares, A. C. (2012). A concorrência na economia portuguesa: uma visão sobre os setores transacionável e não transacionável. Boletim Económico da Primavera do Banco de Portugal, 45-62.

Bain, J. S. (1968). Industrial organization (2nd edition), New York: John Wiley \& Sons.

Barbosa, N. \& Eiriz, V. (2011). Regional variation of firm size and growth: the Portuguese case. Growth and Change, 42(2), 125-158.

Barrios, S., Bertinelli, L., Strobl, E. \& Teixeira, A. (2005). The dynamics of agglomeration: evidence from Ireland and Portugal. Journal of Urban Economics, 57(1), 170-188.

Bikker, J. A. \& Haaf, K. (2002). Measures of competition and concentration in the banking industry: a review of the literature. Economic \& Financial Modelling, 9, 53-98.

Blackorby, C., Donaldson, D. \& Weymark, J. A. (1982). A normative approach to industrial-performance evaluation and concentration indices. European Economic Review, 19(1), 89-121.

Borenstein, S., Bushnell, J. \& Knittel, C. R. (1999). Market power in electricity markets: beyond concentration measures. The Energy Journal, 20(4), 65-88.

Campos, J. \& Vega, G. (2003). Concentration measurement under cross-ownership: the case of the Spanish electricity sector. Journal of Industry, Competition and Trade, 3(4), 313-335.

Carvalho. L. \& Pinto, S. (2013). Portuguese knowledge intensive business services: what do we know about them? Tourism \& Management Studies, 9(1), 101-108.

Demsetz, H. \& Lehn, K. (1985). The structure of corporate ownership: causes and consequences. Journal of Political Economy, 93(6), 1155-1177.

Ellison, G \& Glaeser, E. (1997). Geographic concentration in U.S. manufacturing industries: a dartboard approach. Journal of Political Economy, 105(5), 889-927.

European Communities (2003). Business Register Recommendations Manual (2003 Edition), Luxembourg: Office for Official Publications of the European Communities.

Eurostat \& OECD (2007). Eurostat-OECD Manual on Business Demography Statistics. Paris: OECD Publishing.

Faustino, H. C. (1995) A evolução da concentração industrial em Portugal para o período 1982-1992. Portuguese Journal of Management Studies, II(3), 13-43.

Ginevičius, R. \& Čirba, S. (2007). Determining market concentration. Journal of Business Economics \& Management, 8(1), 3-10.

Ginevičius, R. \& Čirba, S. (2009). Additive measurement of market concentration. Journal of Business Economics \& Management, 10(3), 191-198.

Hall, M. \& Tideman, N. (1967) Measures of concentration. Journal of the American Statistical Association, 62(317), 162-168.

Herfindahl, O. C. (1950). Concentration in the steel industry. Doctoral Dissertation, Columbia University.

Instituto Nacional de Estatística [INE] (2010). Sistema de Contas Integradas das Empresas - Nota metodológica, Lisboa.

Kelly, W. A. (1981). A Generalized Interpretation of the Herfindahl Index. Southern Economic Journal, 48(1), 50-57.

Matsumoto, A., Merlone, U. \& Szidarovszky, F. (2012). Some notes on applying the Herfindahl-Hirschman Index. Applied Economics Letters, 19(2), 181-184.

McIntosh, C. \& Hellmer, S. (2012) Necessary and sufficient conditions in merger control: the use of $\mathrm{HHI}$ and threshold value. Applied Economics, 44(7), 867-878.

Melnik, A., Shy, O. \& Stenbacka, R. (2008). Assessing market dominance. Journal of Economic Behavior \& Organization, 68(1), 6372.

OECD (2006). Structural and Demographic Business Statistics 2006. Paris: OECD Publishing.

OECD (2008). OECD Glossary of Statistical Terms. OECD Glossaires. Paris: OECD Publishing.

Resende, M. (1994). Medidas de concentração industrial: uma Resenha. Análise Econômica, 12(21-22), 24-33.
Resende. M. \& Wyllie, R. (2005). Aglomeração industrial no Brasil: um estudo empírico. Estudos Econômicos, 35(3), 433-460.

Rhoades, S. A. (1993). The Herfindahl-Hirschman Index. Federal Reserve Bulletin, 79, 188-189.

Ruiz-Valenzuela, J., Moreno- Serrano, R. \& Vayá-Valcarce, E. (2007). Has concentration evolved similarly in manufacturing and services? A sensitivity analysis. IREA-Working Papers, IR07/008.

Sarmento E. M \& Nunes, A. (2012). The dynamics of employer enterprise creation in Portugal over the last two decades: a firm size, regional and sectoral perspective. Notas Económicas, 36, 7-19.

Sarmento, E. M. \& Nunes, A. (2014). Business creation in Portugal: a viewpoint on data comparison, Journal of Enterprising Culture, 22(1), 111-132.

Scherer, F. M. (1965). Size of Firm, Oligopoly and Research: A Comment. Canadian Journal of Economics and Political Science, 31(2), 256-266.

Scherer, F. M., Long, W.F, Martin, S., Mueller, D. C., Pascoe, G., Ravenschaft, D. J., Scott, J. T. \& Weiss, L. W. (1987). The validity of studies with line of business data: comment. The American Economic Review, 77(1), 205-217.

Shapiro, C. (2010). The 2010 horizontal merger guidelines: from hedgehog to fox in forty years. Antitrust Law Journal, 77(1), 49-107. Weinstock, D. (1982). Using the Herfindahl Index to measure concentration. The Antitrust Bulletin, 27(2) 285-301.

Submetido: 12.05 .2014

Aceite: 28.11 .2014 